\title{
Urinary bladder agenesis with bilateral single system vaginal ectopic ureters in adult
}

\author{
Rohini Gupta Ghasi $^{1 *}$, Bindu Bajaj ${ }^{2}$ \\ ${ }^{1}$ Department of Radiodiagnosis, VMMC and Safdarjung Hospital, New Delhi, India \\ ${ }^{2}$ Department of Obstetrics and Gynaecology, VMMC and Safdarjung Hospital, New Delhi, India
}

Received: 03 October 2016

Accepted: 28 October 2016

\section{*Correspondence:}

Dr. Rohini Gupta Ghasi,

E-mail: rohini1912@gmail.com

Copyright: $\odot$ the author(s), publisher and licensee Medip Academy. This is an open-access article distributed under the terms of the Creative Commons Attribution Non-Commercial License, which permits unrestricted non-commercial use, distribution, and reproduction in any medium, provided the original work is properly cited.

\section{ABSTRACT}

Agenesis of urinary bladder is an extremely rare condition with only 60 cases and 22 live births being reported previously. Ureteric ectopia is a must for survival. We present a unique case of bladder agenesis detected in adulthood where bilateral single system ureters were draining ectopically in a grossly dilated vagina in normally developed female genital tract.

Keywords: Agenesis, Urinary bladder, Vaginal ectopic ureters

\section{INTRODUCTION}

$80 \%$ of ectopic ureters occur in a duplicated system. Bilateral single system ectopic ureters with absence of urinary bladder are an extraordinarily rare occurrence. Majority of these patients are female and are detected in early postnatal period with dribbling of urine. ${ }^{1}$ A unique case is presented in this report where late diagnosis of bilateral vaginal ectopic ureters was made in adulthood.

\section{CASE REPORT}

A 22 year old married female was referred to Radiology Department for an MCU study for increased frequency of micturition. The bladder was filled retrograde through the perineal orifice presumed to be the urethra. The dome of the presumed bladder was abnormally flattened (Figure 1) the patient voided on command. An ultrasound KUB was done to look for the abnormal shape of bladder. There was severe bilateral hydronephrosis. The ureters, which were traced till the pelvis where they were seen to drain into the fluid filled structure which was continuous with cervix and uterus indicating a dilated vagina (Figure 2). The urinary bladder was not visualized.
Further inquiry from the patient revealed that she had increased frequency of micturition ever since she could remember and the frequency had increased after her marriage since four months. There was no history of continuous dribbling. Local examination of the perineum revealed a normally positioned urethra and vulval opening at the vestibule.

A vaginogram was done which filled up the large capacious vaginal cavity. Patient could hold the contrast in the vagina and void on command. There was reflux into the right ureter (Figure 3a, b).

Her serum urea and creatinine levels were mildly elevated. An NCCT KUB was done which revealed severely hydronephrotic bilateral kidneys. There was rim calcification in the left ureteric wall and pelvicalyceal system (PCS) with milk of calcium in PCS. The ureters were draining into anterior wall of dilated vagina, which lay immediately posterior to the retropubic fat with no intervening bladder tissue (Figure 4a, b).

MR urogram was also done which confirmed the above findings. A small T2 hypointense soft tissue was seen in the retropubic area representing rudimentary bladder, 
which merged with the anterior wall of vagina in midline and was continuous with urethra (Figure 5a, b).

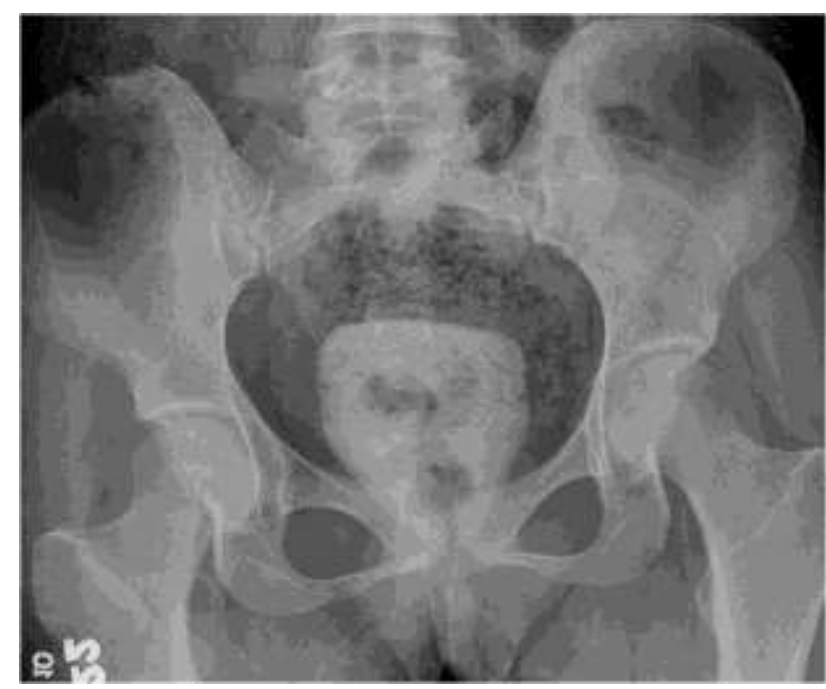

Figure 1: Full bladder phase in MCU study showing abnormal flattened dome of the presumed urinary

bladder. There is no contrast leakage indicating continence.

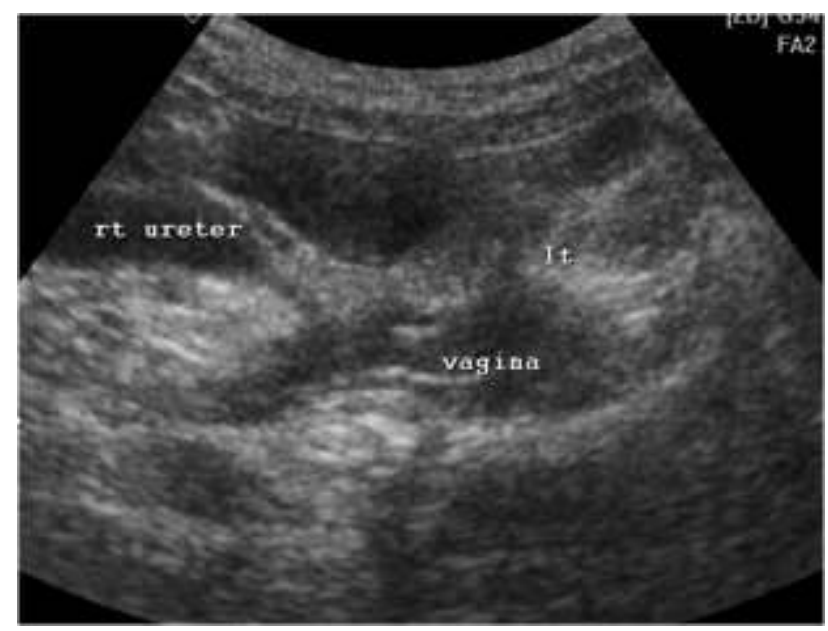

Figure 2: Ultrasound of pelvic region showing absence of urinary bladder. Right ureter is dilated while left ureter is cord like and both are ectopically draining into the vagina.

A diagnosis of urinary bladder agenesis with bilateral ureteric ectopia into vagina was made.

Patient and her family was counselled for a neobladder reconstruction and ureteric re-implantation surgery but unfortunately was reluctant and the patient was lost to follow up.

\section{DISCUSSION}

Agenesis of urinary bladder is an extremely rare condition with only 60 cases and 22 live births having been reported previously. ${ }^{1}$ Ectopic ureteric insertion is mandatory for survival. To the best of our knowledge, there are 3 previous published reports where the bilateral single system vaginal ectopic ureters in association with urinary bladder agenesis are reported. ${ }^{2,3}$ Three other cases of bilateral ectopic ureters opening into urogenital sinus are reported. ${ }^{1,4}$

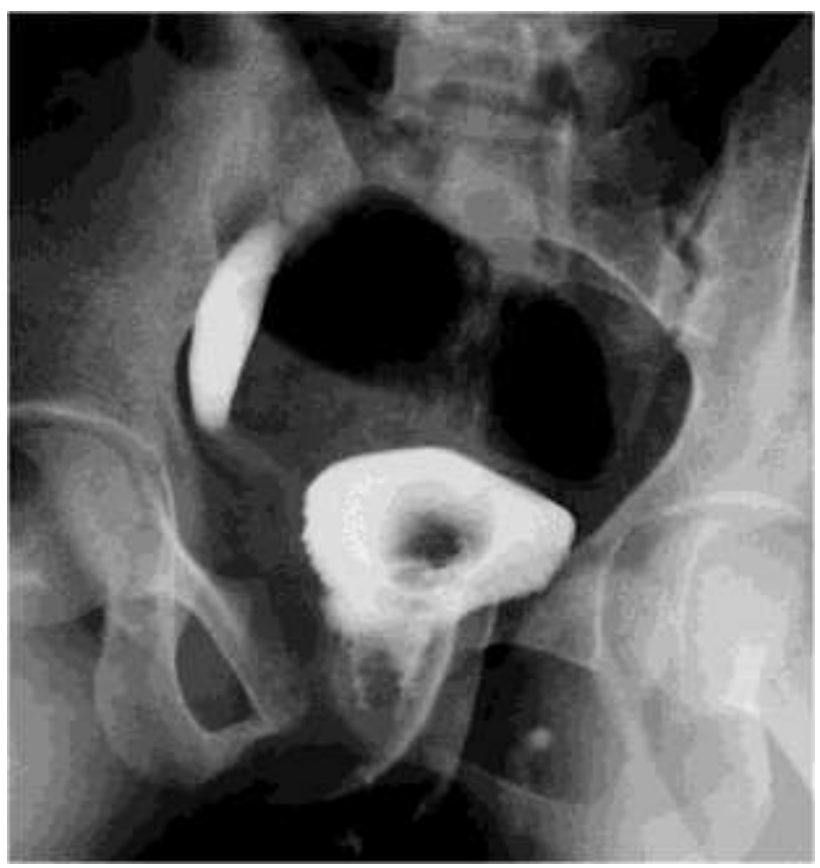

Figure 3a: Vaginogram with Foley's bulb in inflated position showing markedly distended vaginal cavity with typical vaginal mucosal appearance. There is spontaneous reflux into right ureter.

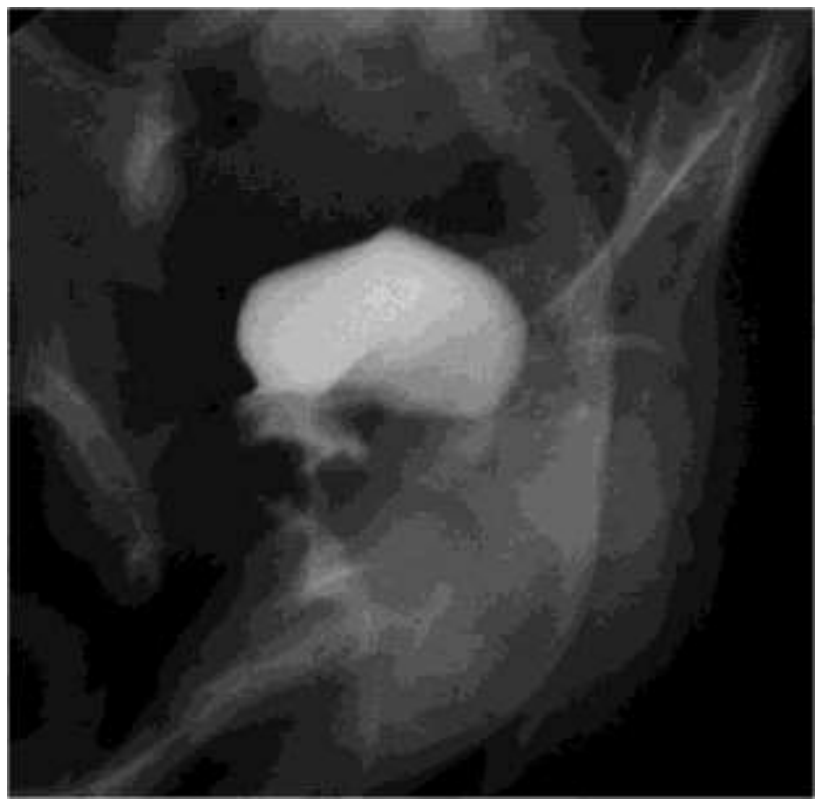

Figure 3b: Voiding phase of vaginogram showing the patient could void voluntarily on command.

Urinary bladder develops from the vesicourethral canal formed from the urogenital sinus, while the ureteric buds 
develop from the outpouching from mesonephric ducts. The ureteric ducts open into the posterior wall of the vesicourethral canal. In absence of any anorectal abnormalities, the embryological error may occur after the separation of cloaca into urogenital sinus and anorectal canal. If the ureters fail to open into the vesicourethral canal, there is lack of its distension with urine and failure of bladder development. Ureters may then open ectopically via embyrological remnants of mesonephric ducts into the Mullerian system. ${ }^{5}$ This is a rare embryological aberration and more so with normal Mullerian development as was present in our case.

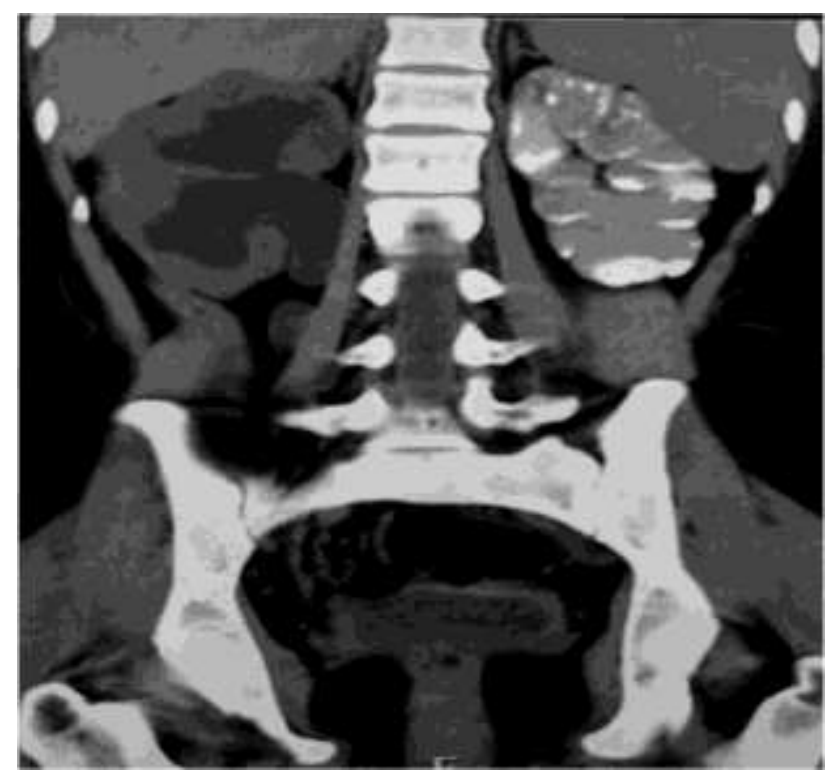

Figure 4a: Coronal reconstructed NCCT image. Bilateral severe hydronephrosis and milk of calcium in left PCS.

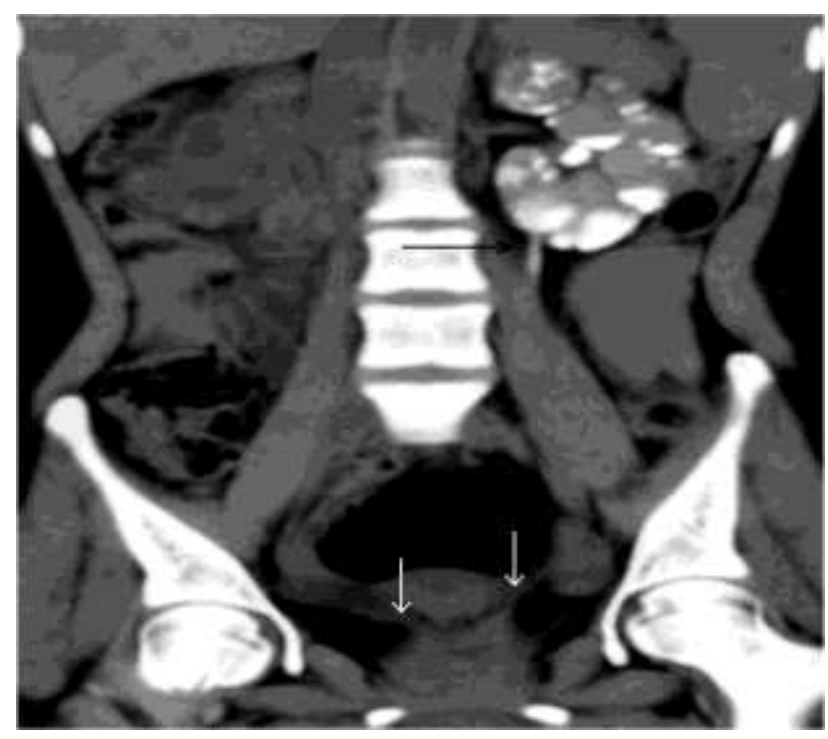

Figure 4b: Coronal reconstructed NCCT image. Left ureter is seen as a calcified cast. Bilateral ureters are draining into the vagina (white arrows).

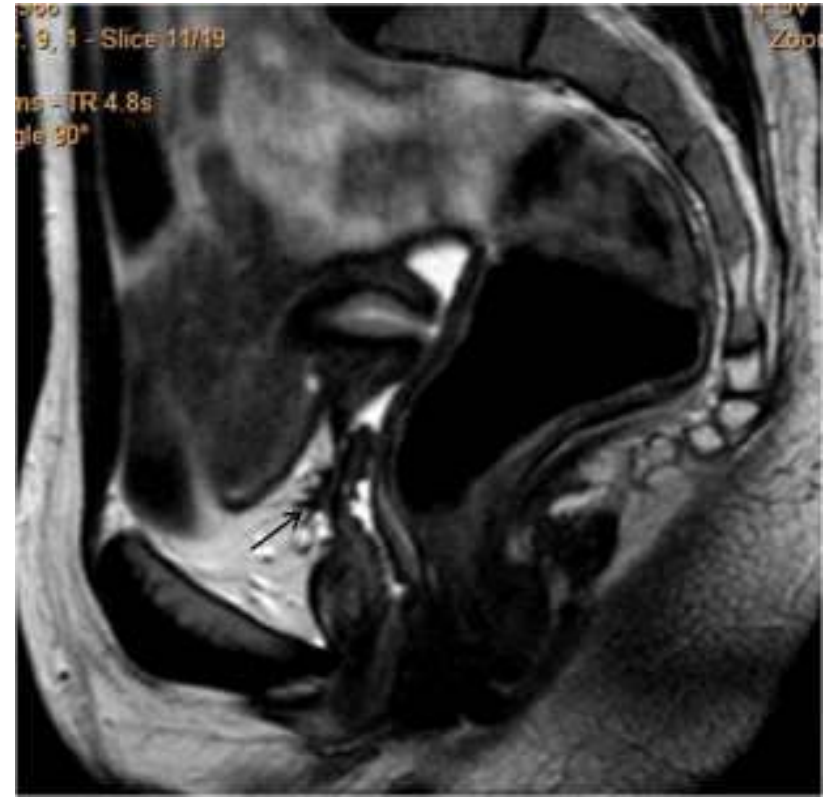

Figure 5a: Sagittal T2-weighted MRI image shows hypointense small retropubic soft tissue of rudimentary bladder (arrow), merging into anterior vaginal wall.

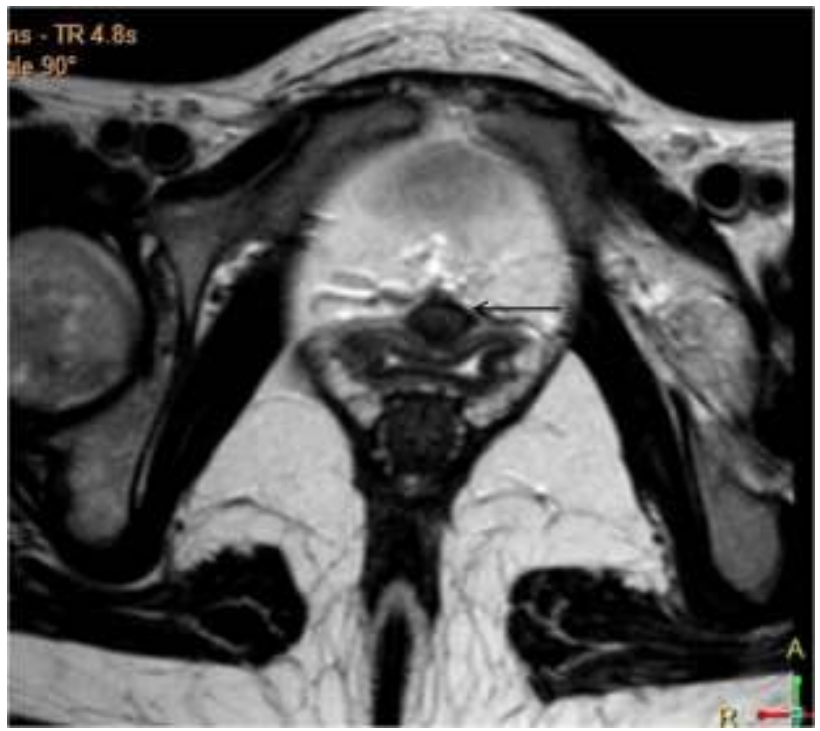

Figure 5b: Axial T2-weighted MRI image shows the normally developed urethra (arrow) anterior to the vagina.

Ectopic ureters typically present with continuous dribbling of urine in childhood. However, absence of incontinence in ureteric ectopia has been explained by the fact that ureters course through some portion of urethral sphincter musculature. ${ }^{6}$ Also, similar phenomenon has been noted in a previous case report of adult female wherein the patient had trained herself to hold urine in vagina by contraction of pelvic musculature. ${ }^{2}$ It is possible that the patient presented in our case after marriage due to aggravation of frequency due to hymenal rupture. 
MRI was crucial investigation in our case with deranged renal function where its superior soft tissue resolution allowed the documentation of exact opening of ureters in the vagina and rudimentary retropubic bladder soft tissue. Importance of MRI has also been highlighted in a previous case in an infant. ${ }^{3}$

The therapeutic options in bilateral single system ectopia are a matter of debate and sparingly described due to rarity of occurrence. Our case adds to the literature of bilateral single system vaginal ureteric ectopia with bladder agenesis and also gives the complete radiological spectrum in this rare condition.

Funding: No funding sources Conflict of interest: None declared Ethical approval: Not required

\section{REFERENCES}

1. Nazim SM, Zaidi Z. Bilateral ectopic ureters with bladder agenesis. J Pak Med Assoc 2012;62(10):1086-9.

2. Mandal S, Jagadheesan G, Kamal M, Mukherjee S, Das R, Karmakar D. Bilateral Single Ectopic Ureters
Draining Into a Grossly Dilated Vagina in an Adolescent Female. Korean Journal of Urology. 2013;54(7):482.

3. Chen CY, Tsao TF, Chang HM, Chen SL, Chen SM, Hung TW, et al. Surg Radiol Anat. 2012;34(1):8992.

4. Singh B, Pathak H, Andankar M. Bilateral singlesystem ectopic ureters opening into vaginalized urogenital sinus. Indian Journal of Urology. 2010;26(1):126.

5. Beroccal T, Lopez-Pereira P, Arjonilla A, Gutierrez J. Anomalies of the Distal Ureter, Bladder, and Urethra in Children: Embryologic, Radiologic, and Pathologic Features. Radio Graphics. 2002;22:113964.

6. Yoshioka M, Okamoto E, Nojima M, Ihara H, Shima $\mathrm{H}$, Ikoma F, et al. Ectopic ureter opening to vestibule without urinary incontinence: a case report. Hinyokika Kiyo. 1992;38(8):945-8.

Cite this article as: Ghasi RG, Bajaj B. Urinary bladder agenesis with bilateral single system vaginal ectopic ureters in adult. Int $\mathrm{J}$ Reprod Contracept Obstet Gynecol 2016;5:4499-4502. 